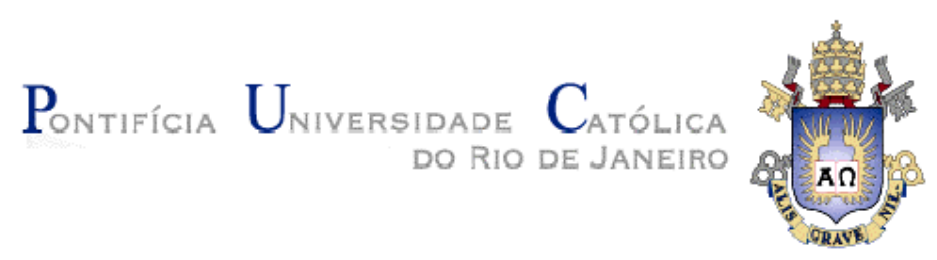

Lucas Barros de Castro

\title{
Ensino de História na fazenda Ponte Alta:
História, cultura \& educação \\ Ensino de História na fazenda Ponte Alta:
História, cultura \& educação
}

Dissertação de Mestrado

Dissertação apresentada como requisito parcial para obtenção do grau de Mestre pelo Programa de Pós-Graduação em Educação do Departamento de Educação da PUC-Rio.

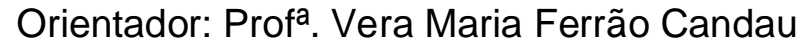




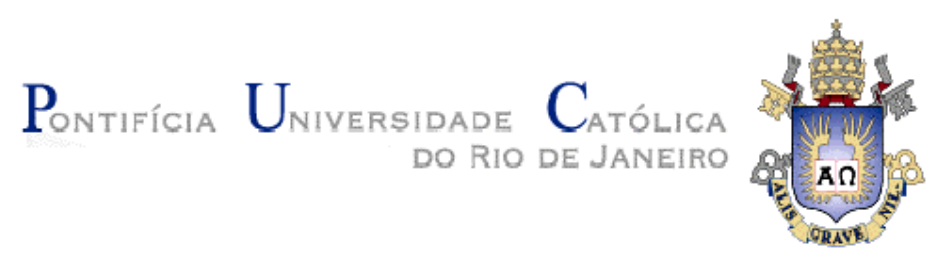

Lucas Barros de Castro

\title{
Ensino de História na fazenda Ponte Alta: \\ História, cultura \& educação
}

\begin{abstract}
Dissertação apresentada como requisito parcial para obtenção do grau de Mestre pelo Programa de Pós-Graduação em Educação do Departamento de Educação do Centro de Teologia e Ciências Humanas da PUC-Rio. Aprovada pela Comissão Examinadora abaixo assinada.
\end{abstract}

\author{
Prof ${ }^{a}$ Vera Maria Ferrão Candau \\ Orientadora \\ Departamento de Educação - PUC-Rio \\ Prof ${ }^{a}$ Patrícia Coelho da Costa \\ Departamento de Educação - PUC-Rio
}

Prof ${ }^{a}$ Helena Maria Marques Araújo UERJ

Profa Denise Portinari Coordenadora Setorial do Centro de Teologia e Ciências Humanas

Rio de Janeiro, 09 de abril de 2013. 
Todos os direitos reservados. É proibida a reprodução total ou parcial do trabalho sem autorização da universidade, da autora e do orientador.

\section{Lucas Barros de Castro}

Historiador formado pela Universidade do Estado do Rio de Janeiro - UERJ. Bacharelado e Licenciatura plena concluídos no $1^{\circ}$ semestre de 2005. Guia nacional de turismo da EMBRATUR, formado pela Marc Apoio no Rio de Janeiro em 2004. Já lecionou em escolas públicas e privadas do Rio de Janeiro como o CAP UERJ, CAP UFRJ, Grupo Faria Brito, CEAT e Padre Antônio Vieira. Pós-graduação pela PUC-RIO formado na especialização Lato senso em Educação Ambiental; sociedade, ambiente e sustentabilidade no ano de 2011. Defesa da dissertação de Mestrado em Educação pela PUC-RIO realizada no dia 09 de abril de 2013.

Ficha Catalográfica

Castro, Lucas Barros de

Ensino de História na fazenda Ponte Alta: história, cultura e educação / Lucas Barros de Castro ; orientadora: Vera Maria Ferrão Candau. - 2013.

169 f. : il. ; $30 \mathrm{~cm}$

Dissertação (mestrado)-Pontifícia Universidade Católica do Rio de Janeiro, Departamento de Educação, 2013. Inclui bibliografia

1. Educação - Teses. 2. Historiografia. 3. Espaços educativos não formais. 4. Cultura. 5. Ensino de história. I. Candau, Vera Maria Ferrão. II. Pontifícia Universidade Católica do Rio de Janeiro. Departamento de Educação. III. Título. 
Graças a Deus, sou um homem de sorte, educado por três lindas e dedicadas mulheres que me ensinaram a viver, amar, ler e a ser feliz.

A Lilian, amada e inseparável mãe, batalhadora e eterna educadora; a Maria Erlanda, avó dedicada, matriarca de todos nós e responsável por tudo que sou; a Maria Ignez, historiadora, amiga e conselheira sempre presente, tia este trabalho é nosso.

Ao meu querido pai, Mauro. Meu herói, exemplo único de hombridade e cordialidade. Maior e eterno amigo, pai saiba sempre que te amo muito.

Dedicatória especial para minha filha, verdadeiro caminho ao mundo do amor e da felicidade. Para ti princesa Maria, por tudo que me ensina e faz ser. Você é a minha vida, flor.

A sempre presente equipe nas atividades de campo nestes últimos anos, especialmente: Fred, Arno, Verônica, Eduardo, Ana, Flávio e Bruno. É uma honra trabalhar com todos, admiro vocês. Obrigado pelas experiências e bons momentos compartilhados.

A toda equipe da Pousada Fazenda Ponte Alta, especialmente

Roberto, Michele e Vandeir. Esta pesquisa é um pequeno reconhecimento ao lindo trabalho de vocês, parabéns.

A todos os alunos com que tive oportunidade de trabalhar e conviver, sou grato pelos ensinamentos e viagens que tivemos juntos. 


\section{Agradecimentos}

A professora Hedy, mestra do ambiente, sempre cordial e solicita. Agradeço por todo o apoio, carinho e conhecimentos dispensados.

As professoras do CAP UERJ, historiadoras e batalhadoras Helena e Sônia. Serei sempre grato pelo apoio, incentivos profissionais e acadêmicos. Muito obrigado, se hoje sou professor e educador de História, devo isto a vocês. Valeu!

Gratidão particular à direção, a secretaria e ao núcleo pedagógico do CAP UERJ, especialmente os coordenadores Miguel e Lincoln, e a parceira/patrocinadora, Lúcia. Pelas oportunidades e o constante incentivo na escola, muito obrigado.

As coordenadoras Cristina e Gilda, respectivamente dos colégios SION e Espaço Total. Sou muito grato pelos bons momentos juntos vividos, por acreditarem sempre nas experiências e pelas oportunidades de aprendizagem em campo.

A todos os professore (a)s e coordenadores (as) do PPGE da PUC-RIO, especialmente Zaia, Waleska, Rosália e Marcelo. Muito obrigado por todo o apoio, paciência e incentivos dispensados. Serei sempre grato pela ajuda e colaboração de vocês nesta difícil e conturbada caminhada acadêmica.

A querida Vera, que aceitou este enorme desafio e abraçou, desde o inicio esta verdadeira Cruzada com sua habitual sabedoria, experiência e, cordialidade.

Não tenho palavras para expressar meus agradecimentos a ti, Vera.

Obrigado por tudo e peço que me desculpe pelos transtornos, problemas e incômodos causados. 


\section{Resumo}

Castro, Lucas Barros; Candau, Vera Maria. Ensino de História na Fazenda Ponte Alta: História, cultura \& educação. Rio de Janeiro, 2013. 169p. Dissertação de Mestrado - Departamento de Educação, Pontifícia Universidade Católica do Rio de Janeiro.

O trabalho entrelaça historiografia, espaços não formais, cultura e ensino de história. A pesquisa busca compreender as práticas educativas desenvolvidas no roteiro guiado da Pousada Fazenda Ponte Alta (PFPA) e suas relações com o ensino de história nas escolas cariocas. Está estruturado em três capítulos, além da introdução e considerações finas. Após a introdução, o capítulo II aborda as diversas reescritas historiográficas desenvolvidas pela Escola dos Annales e pela Nova História Cultural, assim como aprofunda no sentido e relevância da chamada educação não formal. Termina com reflexões direcionadas as propostas didáticas observadas hoje no ensino de história. O terceiro capítulo realiza uma descrição da PFPA: história, arquitetura, características centrais, os atuais serviços e, principalmente, analisa as atividades e dinâmicas educativas realizadas no local. O quarto e último capítulo está centrado na análise dos dados construídos através da pesquisa, cujas estratégias metodológicas foram revisão bibliográfica, análise documental, observações e entrevistas. Nas considerações finais destaca-se que o espaço tem consolidado seu roteiro histórico como importante ferramenta e prática educativa. Acreditamos que a PFPA possibilita avanços no ensino de história ao promover a ampliação das fontes de pesquisa, de experiências e dinâmicas pedagógicas e, assim, contribui para o enriquecimento do ensino de história nas escolas do Rio de Janeiro, particularmente no Ensino Fundamental.

\section{Palavras-chave:}

Historiografia; Espaços educativos não formais; Cultura; Ensino de história. 


\section{Abstract}

Castro, Lucas Barros; Candau, Vera Maria. (Advisor). Teaching History in High Bridge Farm: History, Culture \& Education. Rio de Janeiro, 2013. 169p. MSc. Dissertation - Departamento de Educação, Pontifícia Universidade Católica do Rio de Janeiro.

The work weaves together non-formal spaces, historiography, culture and history teaching. The research tries to understand the educational practices developed in the screenplay of Pousada Fazenda Ponte Alta guided (PFPA) and their relationships with the teaching of history in schools in Rio. It is structured in three chapters, besides the introduction and considerations. After the introduction, chapter II discusses the various historiographical rewritten developed by the Annales school and New Cultural history, as well as deepens in meaning and relevance of the so-called non-formal education. It ends with reflections directed to didactic proposals observed today in history teaching. The third chapter is a description of the PFPA: its history, architecture, key features, the current services offered and, above all, educational activities and dynamic analyses carried out on site. The fourth and final chapter is focused on the analysis of data built through research, whose methodological strategies were bibliographical revision, document analysis, observation and interviews. In the final considerations it stands out that the space has consolidated its historic route as an important tool and educational practice. We believe that the PFPA provides updates in teaching history to promote the expansion of research sources, experiences and pedagogical dynamics and thus contributes to the enrichment of history teaching in schools of Rio de Janeiro, particularly in elementary school.

\section{Key-words:}

Historiography; Non formal educative spaces; Culture; History teaching. 


\section{Sumário}

1. Introdução .................................................................. 14

1.1. Justificativa ............................................................. 18

1.2. Relevância ................................................................... 19

1.3. Questões norteadoras da pesquisa ................................... 20

1.4. Objetivos norteadores da pesquisa .................................. 21

1.5. Procedimentos metodológicos da pesquisa ........................ 23

1.6. Estrutura da dissertação ............................................. 31

2. História, cultura e educação: desafios no ensino de História ...... 33

2.1. Correntes atuais da História ................................................ 34

2.2. As relações entre a educação formal e não formal ................... 45

2.3. A didática e as práticas pedagógicas no ensino de História contemporânea ..................................................................... 52

3. A Pousada Fazenda Ponte Alta - PFPA .................................... 67

3.1. História, arquitetura e informações centrais ............................ 69

3.2. O roteiro pedagógico guiado e os espaços educativos visitando nosso passado ......................................................... 78

4. A experiência educativa da PFPA - vivendo, sentindo e tateando a história

88

4.1. Os sujeitos educativos da fazenda - a Ponte Alta em corpo e alma

4.1.1. Tornando-se historiadores para poder trabalhar as temáticas da PFPA

4.1.2. O roteiro educativo da PFPA e a educação formal - "Nosso projeto é para os educadores trabalharem o conteúdo depois, na sala de aula"

4.2. A ótica dos educadores das escolas - passeando pelo 
passado e construindo o amanhã

4.2.1. Formação acadêmica e ensino de história - "O conhecimento histórico é produzido à luz de interpretação" .

101

4.2.2. A experiência de campo e a educação formal - "Acredito que atividades realizadas em espaços não formais de educação são sempre uma grande ferramenta pedagógica"

4.3. O antes e o depois da experiência: "Estar imerso em uma cultura é a melhor forma de aprendê-la e à sua história: é vivendo, sentindo pelos poros, tateando a história"

4.4. Olhares interdisciplinares - as outras disciplinas e o roteiro educativo da PFPA

125

5. Considerações finais - $\mathrm{O}$ ensino de história em perspectiva ......

133

6. Referências Bibliográficas

142

Anexos 


\section{Lista das imagens, mapas e folders}

Todas as referencias fotográficas, visuais e/ou institucionais foram cedidas pelos profissionais da fazenda Ponte Alta, especialmente Roberto e Vandeir. Imagens pedagógicas feitas pelo fotografo e colaborador Bruno Avellar.

A listagem direciona-se as imagens presentes no corpo do trabalho, excetuando-se os materiais constantes em anexo. Agradeço a vocês pela colaboração e cessão das imagens e fotos presentes nesta dissertação.

Consta no material virtual da dissertação anexo em CD incluindo Power point de defesa, outras imagens e gráficos/tabelas das entrevistas.

Figura 1 - Entrada principal da PFPA .....

67

Figura 2 - Alunos do CAP UERJ em foto na escadaria da casa grande, 2010

Figura 3 - Vista panorâmica do quadrilátero funcional original da PFPA 69

Figura 4 - Foto da fachada da casa grande

Figura 5 - Mapa da fazenda Ponte Alta utilizado nos materiais de

divulgação 73

Figura 6 - Foto da fachada vista pelos grupos na chegada à PFPA

Figura 7 - Alunos do CAP UERJ preparam-se para dinâmice ambiental no quadrilátero, 2010

Figura 8 - À esquerda, vista panorâmica das senzalas suspensas ..

Figura 9 - À direita, espaço externo das senzalas, em detalhe, ao fundo, alunos do CAP UERJ

Figura 10 - Atividade produtiva do local - pecuária para corte . 78

Figura 11 - À direita atividade complementar, criação de cavalos .... 78

Figura 12 - Baronesa na maquete com turma do CAP, à esquerda . 
Figura 13 - Início da visita na maquete, alunos do SION em 2012, à direita

Figura 14 - Alunos do CAP UERJ, 2010 acompanham a Baronesa e suas explicações sobre a roda d'água

Figura 15 - À esquerda, objetos de tortura como o famoso vira mundo

Figura 16 - À direita, alunos do CAP UERJ participam de visita ao Museu dos escravos guiados pela baronesa

Figuras 17/18 - Alunos do Colégio SION participam da atividade do Jongo cantando e dançando em 2012 82 Figura 19 - A Ponte Alta convida seus visitantes a um passeio pela história. Imagem de divulgação e apresentação do Sarau Imperial ... 83 Figura 20 - Apresentação do Sarau Imperial, à esquerda ................. 84 Figura 21 - Alunos do SION vestidos à caráter, em 2012 ................ $\quad 84$ Figura 22 - Sarau musical, à esquerda alunos do CAP UERJ em 2010

Figura 23 - À direita, estudantes do Colégio SION participam das danças em 2012 85 Figuras 24/25 - Folders / convites do sarau do Gêgê 


\section{Lista de Abreviaturas da Pesquisa}

ALERJ - Assembléia Legislativa do Estado do Rio de Janeiro.

APA - Área de Proteção Ambiental.

AR - Arquivo Nacional.

CAP UERJ - Instituto de Aplicação Fernando Rodrigues da Silveira.

CAP UFRJ - Instituto de Aplicação da Universidade do Estado do Rio de Janeiro.

EF - Ensino Fundamental.

NHC - Nova História Cultural.

PARNASO - Parque Nacional da Serra dos Órgãos.

PCN's - Parâmetros Curriculares Nacionais

PFPA - Pousada Fazenda Ponte Alta.

PNI - Parque Nacional de Itatiaia.

PNT - Parque Nacional da Tijuca.

RJ - Rio de Janeiro.

UERJ - Universidade do Estado do Rio de Janeiro.

UFRJ - Universidade Federal do Rio de Janeiro.

UFRS - Universidade Federal do Rio Grande do Sul. 
"O universo e a natureza possuem história. Ela está sendo contada pelas estrelas, pela terra, pelo afloramento e elevação das montanhas, pelos animais, pelas florestas $e$ pelos rios. Nossa tarefa é saber escutar e interpretar as mensagens que eles nos mandam”.

Leonardo Boff 